\title{
Long-Term Follow-Up of Gemogenovatucel-T (Vigil) Survival and Molecular Signals of Immune Response in Recurrent Ovarian Cancer
}

\author{
Rodney P. Rocconi ${ }^{1}$, Laura Stanbery ${ }^{2}$, Luciana Madeira da Silva ${ }^{3}$, Robert A. Barrington ${ }^{3}$, Phylicia Aaron ${ }^{2}$, \\ Luisa Manning ${ }^{2}$, Staci Horvath ${ }^{2}$, Gladice Wallraven ${ }^{2}$, Ernest Bognar ${ }^{2}$, Adam Walter ${ }^{4}$ and John Nemunaitis ${ }^{2, *}$ \\ 1 Mitchell Cancer Institute, Division of Gynecologic Oncology, University of South Alabama, Mobile, \\ AL 36604, USA; rocconi@health.southalabama.edu \\ 2 Gradalis, Inc., 2545 Golden Bear Drive, Suite 110, Carrollton, TX 75006, USA; Inejedlik@gradalisinc.com (L.S.); \\ paaron@gradalisinc.com (P.A.); lmanning@gradalisinc.com (L.M.); shorvath@gradalisinc.com (S.H.); \\ gwallraven@gradalisinc.com (G.W.); ebognar@gradalisinc.com (E.B.) \\ 3 Department of Microbiology and Immunology, University of South Alabama, Mobile, AL 36688, USA; \\ 1silva@health.southalabama.edu (L.M.d.S.); rbarrington@health.southalabama.edu (R.A.B.) \\ 4 Promedica, Sylvania, OH 43560, USA; adam.walterMD@promedica.org \\ * Correspondence: jnemunaitis@gradalisinc.com
}

\section{check for} updates

Citation: Rocconi, R.P.; Stanbery, L.; Madeira da Silva, L.; Barrington, R.A.; Aaron, P.; Manning, L.; Horvath, S.; Wallraven, G.; Bognar, E.; Walter, A.; et al. Long-Term Follow-Up of Gemogenovatucel-T (Vigil) Survival and Molecular Signals of Immune Response in Recurrent Ovarian Cancer. Vaccines 2021, 9, 894. https:// doi.org/10.3390/vaccines9080894

Academic Editor: Kyong-Hwa Park

Received: 14 June 2021

Accepted: 6 August 2021

Published: 12 August 2021

Publisher's Note: MDPI stays neutral with regard to jurisdictional claims in published maps and institutional affiliations.

Copyright: (c) 2021 by the authors. Licensee MDPI, Basel, Switzerland. This article is an open access article distributed under the terms and conditions of the Creative Commons Attribution (CC BY) license (https:// creativecommons.org/licenses/by/ $4.0 /)$.
Abstract: Aim: To determine the relationship between gene expression profile (GEP) and overall survival (OS) by NanoString following treatment with Vigil. Patients and Methods: Recurrent ovarian cancer patients $(n=21)$ enrolled in prior clinical trials. Results: GEP stratified by TIS ${ }^{\mathrm{HIGH}}$ vs. TIS ${ }^{\mathrm{LOW}}$ demonstrated OS benefit (NR vs. 5.8 months HR $0.23 ; p=0.0379$ ), and in particular, MHC-II elevated baseline expression was correlated with OS advantage $(p=0.038)$. Moreover, 1 -year OS was $75 \%$ in TIS ${ }^{\mathrm{HIGH}}$ patients vs. $25 \%$ in TIS $^{\mathrm{LOW}}(p=0.03795)$. OS was also correlated with positive $\gamma$-IFN ELISPOT response, 36.8 vs. 23.0 months (HR 0.19, $p=0.0098$ ). Conclusion: Vigil demonstrates OS benefit in correlation with TIS ${ }^{\mathrm{HIGH}}$ score, elevated MHC-II expression and positive $\gamma$-IFN ELISPOT in recurrent ovarian cancer patients.

Keywords: Vigil; immune response; NanoString; TIS; gene expression profile; immunotherapy; ovarian cancer

\section{Background}

Ovarian cancer remains a complex and difficult condition to treat, in part because of the advanced stage at presentation. Using American Cancer Society estimates, 21,750 new cases of ovarian cancer are expected and 13,940 deaths from disease are estimated in the USA in 2020 [1]. With optimal standard of care treatment, including surgical debulking and adjuvant or neoadjuvant chemotherapy consisting of paclitaxel and carboplatin with or without bevacizumab in newly diagnosed patients with advanced surgically resectable disease, 5-year survival rates are only 48\% [2,3]. Patients with stage IV disease have even worse survival, with 5-year rates below 20\% [4]. Additionally, the majority of advancedstage ovarian cancer patients relapse within 2 years [2]. Research has involved developing improved maintenance regimens, which provide improvements in progression-free survival (PFS) [5,6]. In particular, poly (ADP-ribose) polymerase (PARP) inhibitors have shown benefit in prolonging PFS; however, this benefit is predominately in the BRCA1/2 mutant population, with limited efficacy in $B R C A 1 / 2$ wild-type individuals [7-10]. Prognosis in recurrent disease patients unfortunately is much worse; median survival is near 2 years and focus of management is on quality of life support. Recurrent disease patients are rarely curable, although a recent comparison of platinum-sensitive recurrent ovarian cancer patients with the BRCA1/2 mutation in the SOLO-2 study revealed a 5-year overall survival (OS) of $41.6 \%$ with the use of olaparib as second-line or greater maintenance compared to standard of care of $33.3 \%$ [11]. 
Vigil is constructed using harvested autologous tumor tissue and given as an intradermal injection in order to access personal neoantigen display. Tumor cells are transfected with a plasmid containing the GM-CSF gene and a bifunctional short hairpin RNA which targets furin [12]. Successful furin knockdown is demonstrated by downstream inhibition of TGF $\beta 1$ and TGF $\beta 2$, potent immune suppressor cytokines, which have been shown to improve the anticancer immune response when suppressed [12]. Further, immune function and enhanced antigen expression is provided with exogenous GM-CSF production [13]. Vigil has also been shown to increase CD3+/CD8+ circulating mononuclear cells in solid tumor patients [14]. Personal neoantigen display and T cell priming and expansion may point to memory $\mathrm{T}$ cell generation by Vigil.

Previous results have been reported from a Phase I trial in late-stage cancer patients, involving 19 different solid tumor types, who received two different dose levels of Vigil $\left(1 \times 10^{7}\right.$ and $2.5 \times 10^{7}$ cells /injection) [15]. Safety confirmed at both dose levels demonstrated no dose-dependent toxic responses. Previous long-term follow-up of nearly three years identified that $\gamma$-IFN-ELISPOT positivity was correlated with OS advantage to Vigil treatment [16]. Moreover, results from Phase IIa testing of Vigil vs. placebo [17,18] and recently from a Phase IIb clinical trial involving newly diagnosed advanced ovarian cancer patients with a $B R C A 1 / 2$ wild-type genetic profile showed greater clinical benefit, as both relapse-free survival (RFS) and OS were improved [19].

Limited effectiveness of immunotherapy, however, has been seen in ovarian cancer [20-22]. Nonetheless, subsets of patients exhibit durable responses that can exceed 2 years. Several biomarkers have been studied, but no demonstration of distinguishing signals between responders and non-responders has been shown [10-12,23,24]. RNA-based evaluations suggest that specific mutational load, cytolytic activity and neoantigen signatures offer potential predictive indication with immunotherapy [25]. Here, we focus on recurrent ovarian cancer patients and provide additional long-term follow-up including a molecular biomarker profile of this cohort of patients.

\section{Materials and Methods}

\subsection{Study Design}

Vigil plasmid construction and cGMP manufacturing have been previously described $[12,15,17]$. Tumor tissue was excised and processed according to protocol guidelines and shipped to Gradalis, Inc. for vaccine manufacturing. Tissue was processed and transfected as previously described [15]. All recurrent ovarian cancer patients received Vigil at $1 \times 10^{7}$ or $2.5 \times 10^{7}$ cells /injection and were monitored closely for safety during study treatment as described [15]. Long-term follow-up was performed by phone survey and by medial record review. Trials were previously registered as NCT01061840 and NCT01309230.

\subsection{ELISPOT Assay}

ELISPOT was performed as previously described [15,17]. The Enzyme-Linked Immunospot Assay for Interferon Gamma (BD Biosciences, San Jose, CA, USA) was used. A sample was considered positive if $>10$ spots or $2 \times$ baseline was observed. ZellNet Consulting, Fort Lee, NJ provided quantitation.

\subsection{RNA Isolation and Gene Expression Analysis}

Pretreatment clinical specimens were collected as specified in the clinical protocol and consisted of frozen cells retained from fresh tissue that were harvested at time of tissue procurement. Total RNA was isolated using RNeasy Mini Kit (Qiagen, Venlo, The Netherlands). Gene expression analysis was conducted using the NanoString ${ }^{\circledR}$ PanCancer Immuno-Oncology $360^{\mathrm{TM}}$ CodeSet using the nCounter ${ }^{\circledR}$ SPRINT platform (NanoString ${ }^{\circledR}$ Technologies, Seattle, WA, USA). This unique 770-plex gene expression panel, which profiles the immune system, tumor and tumor microenvironment, was utilized to characterize individual genes and pathways that shape tumor-immune interactions. An incorporated 
algorithm of 18 specific functional genes known to be associated with immunotherapy response was used to calculate a tumor inflammation score (TIS) by the Nanostring ${ }^{\circledR}$ IO360 Data Analysis Service, in addition to 42 signatures measuring important tumor immune activities and immune cell populations. The weighted scores used for calculation of the TIS and other signatures are NanoString ${ }^{\circledR}$ intellectual property. Differential gene expression analysis between TIS ${ }^{\text {high }}(>6.0)$ and TIS $^{\text {low }}(<6.0)$ samples was performed using the nSolver ${ }^{\mathrm{TM}}$ Analysis Software v4.0 and the nSolver Advanced Analysis package with Benjamin-Yakhteh adjusted $p$-values. Pathway scores obtained in the nSolver Advanced Analysis were analyzed by Graphpad Prism. Good responders were defined as OS $>12$ months and poor responders $\leq 12$ months. T-tests with Welch's correction were used for comparison between groups. Values of $p<0.05$ were considered significant. Heatmaps of signature scores were built using ClustVis (https://biit.cs.ut.ee/clustvis/, accessed on 3 August 2021) [26].

\subsection{Statistics}

Survival was analyzed using Graphpad Prism version 8.3.0 (GraphPad Software, Inc., San Diego, CA, USA) software to generate Kaplan-Meier curves and compare ELISPOT results, which included all recurrent/refractory patients enrolled. OS of patients still alive was censored using the last known date alive and was calculated from time of surgery/tissue procurement. The hazard ratios (HR) of OS analysis were estimated via a log-rank hazards ratio model. ELISPOT analysis compared ELISPOT+ and ELISPOTresults using a log-rank hazards ratio model. A one-sided $p$-value of 0.05 or less (log-rank) was considered to indicate statistical significance.

\section{Results}

\subsection{Patient Demographics}

Patient demographics are listed in Table 1. Twenty-one patients were enrolled in the Vigil studies $[12,15,16]$ from May 2010 to December 2014. Patients had received a mean of 2.95 lines of prior systemic therapy as standard of care (range 1-10). A total of 124 vaccine doses were administered. The mean number of Vigil doses administered was 5.9 (range of 1-12). There was no difference in patient demographics including age between the overall population and those undergoing NanoString ${ }^{\circledR}$. At recurrence, prior to study enrollment, patients received a variety of standard of care chemotherapy regimens including carboplatin, cisplatin, gemcitabine and paclitaxel among others. No patients received PARP inhibitors.

Table 1. Patient demographics.

\begin{tabular}{ccc}
\hline & $\begin{array}{c}\text { Recurrent Ovarian Cancer } \\
\text { Patients }\end{array}$ & $\begin{array}{c}\text { NanoString }{ }^{\circledR} \text { Analysis } \\
\text { Recurrent Ovarian Cancer } \\
\text { Patients }\end{array}$ \\
\hline Patients-no. & 21 & 12 \\
\hline Age-years & 61 & 61.5 \\
\hline Median & 59.8 & 59.6 \\
\hline Mean & $39-75$ & $39-75$ \\
\hline Range & $16(76.2)$ & $10(83.3)$ \\
\hline$<65-$ no. $(\%)$ & $5(23.8)$ & $2(16.7)$ \\
\hline$\geq 65-$ no. $(\%)$ & &
\end{tabular}


Table 1. Cont.

\begin{tabular}{ccc}
\hline & $\begin{array}{c}\text { Recurrent Ovarian Cancer } \\
\text { Patients }\end{array}$ & $\begin{array}{c}\text { NanoString Analysis } \\
\text { Recurrent Ovarian Cancer } \\
\text { Patients }\end{array}$ \\
\hline No. of prior lines-no. (\%) & 2 & 2 \\
\hline Median & 2.95 & 3.17 \\
\hline Mean & $1-10$ & $1-10$ \\
\hline Range & 17.4 & 17.3 \\
\hline CA-125 at time of treatment & 150.4 & 170.1 \\
\hline start-no. $(\%)$ & $17.4-1434$ & $8.8-1434$ \\
\hline Median & $11(52.4)$ & $8(66.7)$ \\
\hline Mean & $4(19.0)$ & $2(16.7)$ \\
\hline Range & $6(28.6)$ & $2(16.7)$ \\
\hline$<35$ & & $2(16.7) *$ \\
\hline$\geq 35$ & $3(14.3) *$ & $10(83.3)$ \\
\hline Missing & $18(85.7)$ & \\
\hline Disease at study start-no. $(\%)$ & & \\
\hline No disease & & \\
\hline disease & & \\
\hline Pans & & \\
\hline
\end{tabular}

* Patients had no evidence of disease (NED) $\left({ }^{*}\right.$ two subjects with elevated CA-125, one subject with no visible disease by RECIST after 3rd line chemotherapy) prior to therapy for recurrence before enrolling in trial.

\subsection{Overall Long-Term Survival and Safety}

As shown in Figure 1, Kaplan-Meier analysis of 21 recurrent ovarian cancer patients revealed a $58 \%$ survival rate at 6 years from time of surgery/tissue procurement, which encouragingly demonstrates a plateau maintained for just over 3 years. No long-term serious adverse events or Grade 3/4 Vigil-related toxic effects were observed or reported.

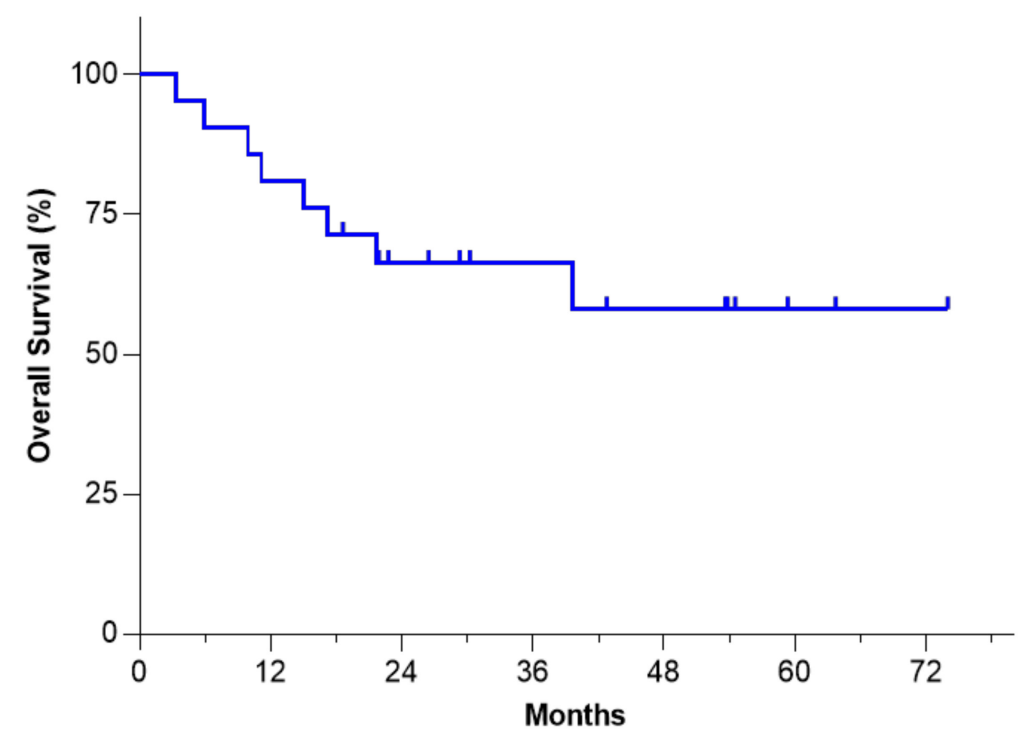

\section{No. at Risk}

Recurrent disease

21 18 12 9 3 2

Figure 1. OS of Vigil-treated recurrent/refractory ovarian cancer patients from time of procurement. 


\subsection{Immune Response Correlation to Overall Survival}

Twenty-one patients were assayed for $\gamma$-IFN-ELISPOT response during Vigil administration: 14 patients were shown to be $\gamma$-IFN-ELISPOT positive, four patients were negative and three were not able to be assessed. Of the four $\gamma$-IFN-ELISPOT-negative patients, two died from disease during the study: one cause of death was unknown and one patient was still alive. From time of tissue procurement (Figure 2A), median OS in $\gamma$-IFN-ELISPOT positive patients was not reached versus 16.1 months for ELISPOT negative patients $(p=0.0098$, HR 0.19 , estimated $95 \%$ CI: $0.021-1.7)$. OS from time of treatment start was similarly improved in $\gamma$-IFN-ELISPOT-positive patients; median was not reached versus 9.5 months, respectively ( $p=0.0079$, HR 0.18, estimated 95\% CI: 0.019-1.7) (Figure 2B).

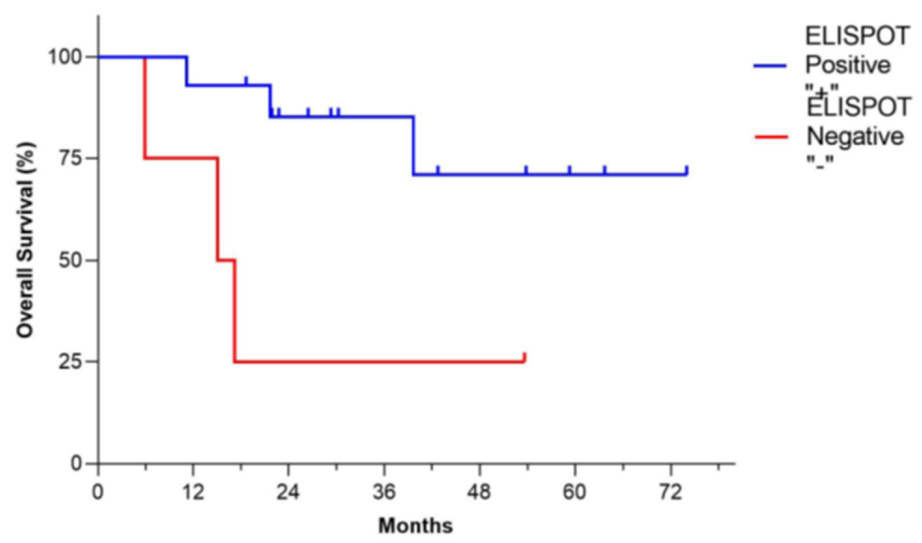

No at Risk

$\begin{array}{llllllll}\text { ELISPOT positive } & 14 & 14 & 10 & 7 & 5 & 3 & 2 \\ \text { ELISPOT negative } & 4 & 4 & 2 & 2 & 2 & & \end{array}$

B

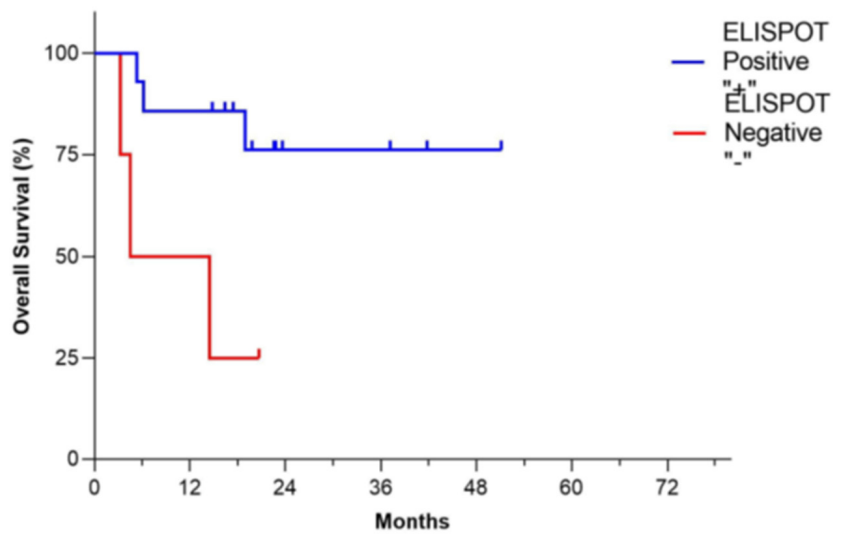

No at Risk

$\begin{array}{llllll}\text { ELISPOT positive } & 14 & 13 & 4 & 4 & 2\end{array}$

ELISPOT negative $4 \quad 3$

Figure 2. Overall survival relationship of Vigil treatment recurrent/refractory ovarian cancer patients by $\gamma$-IFN-ELISPOT-positive vs. $\gamma$-IFN-ELISPOT-negative recurrent ovarian cancer patients from time of tissue procurement $(\mathbf{A})$ and start of treatment (B). 


\subsection{Immune Gene Expression Profiling}

We explored TIS profiles and other gene expression signatures in 12 (who had sufficient tissue available) of the 21 recurrent ovarian cancer patients to assess the ability to detect immune-responsive ("hot") tumors and how it correlates with clinical outcomes in response to Vigil. To apply the TIS score as a tool for patient enrichment, the pre-specified consensus threshold of 6.0 was used [27].

Principal component analysis (PCA) was performed to identify the distribution of signature scores of TIS ${ }^{\mathrm{HIGH}}$ (red) and $\mathrm{TIS}^{\mathrm{LOW}}$ tumors (blue), good responders (red) and poor responders (blue), $\gamma$-IFN-ELISPOT-negative (circles) and $\gamma$-IFN-ELISPOT-positive (squares) and $\gamma$-IFN-ELISPOT not evaluable (triangles) (Figure 3A). This analysis shows that the distance between each dot is related to the similarity between observations in highdimensional space. From these data, we assume that the signature scores associated with patient response to Vigil (good response (GR) vs. poor response (PR)) and $\gamma$-IFN-ELISPOT reactivity (positive/negative) are strongly conserved. The 43 signature scores for each patient are presented on a heatmap in Figure 3B. The scores are grouped by TIS grouping, response status to Vigil and $\gamma$-IFN-ELISPOT reactivity after Vigil treatment. The heatmap shows TIS grouping of $>/<6.0$, and patients who demonstrated a positive or negative $\gamma$-IFN-ELISPOT response are clearly separated. The majority of TIS ${ }^{\mathrm{HIGH}}$ tumors were associated with $\gamma$-IFN-ELISPOT positivity (FANG-OV-1024 was $\gamma$-IFN-ELISPOT-negative). Most good responders were associated with $\gamma$-IFN-ELISPOT positivity, with the exception of FANG-OV-1091 ( $\gamma$-IFN-ELISPOT-negative).

\section{A}

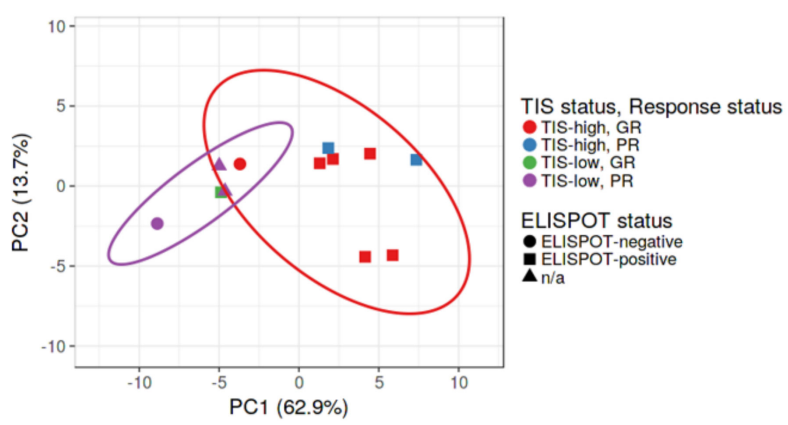

\section{B}

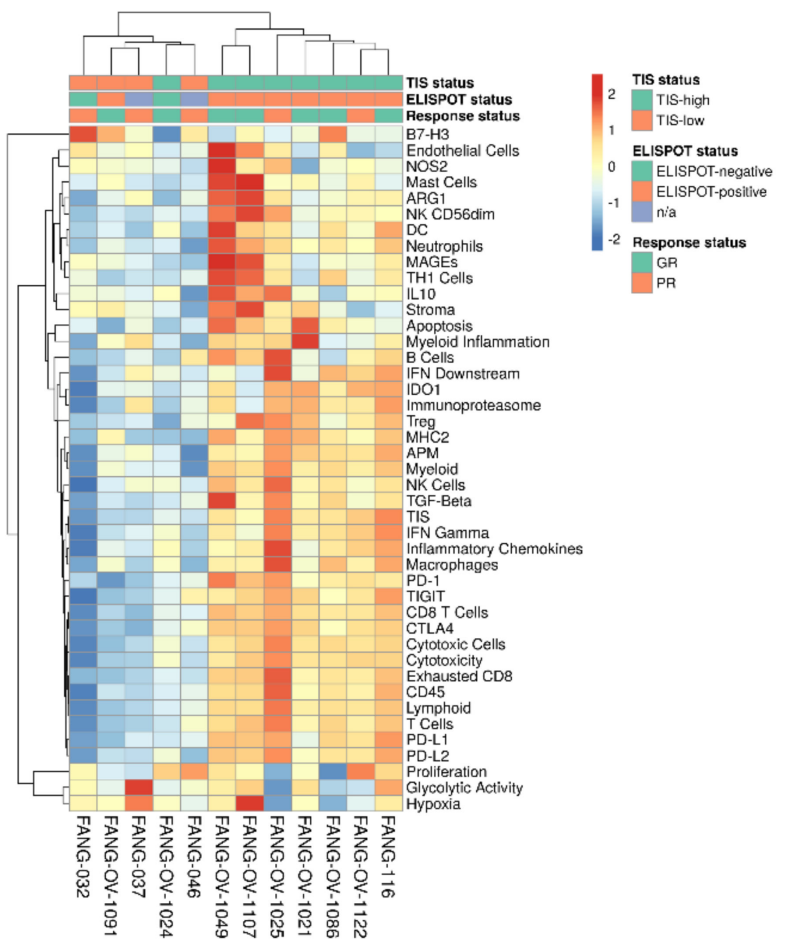

Figure 3. Principal component analysis (PCA) was completed to detect intrinsic clusters between responders to Vigil treatment and $\gamma$-IFN-ELISPOT reactivity post-Vigil treatment as well as possible outliers. $\mathrm{TIS}^{\mathrm{HIGH}}$ good responders (Tumor inflammation score (TIS)) $>6$, OS $>12$ months) post-Vigil treatment $=$ red; TIS ${ }^{H I G H}$ poor responders (TIS score $>6$, OS $<12$ months) post-Vigil treatment $=$ blue; TIS ${ }^{\text {LOW }}$ good responders (TIS score $<6$, OS $>12$ months) post-Vigil treatment $=$ green; TIS ${ }^{\text {LOW }}$ poor responders (TIS score $<6$, OS $<12$ months) post-Vigil treatment $=$ purple; $\gamma$-IFN-ELISPOTnegative $=$ circles; $\gamma$-IFN-ELISPOT-positive $=$ squares; post-Vigil; $\gamma$-IFN-ELISPOT not evaluable $=$ triangle $(\mathbf{A})$ Heatmap of immune pathways stratified by TIS status, response to Vigil therapy and $\gamma$-IFN-ELISPOT status. Blue scale indicates under-expressed genes and red scale upregulated genes (B). 
Immune gene signatures of patient tumors demonstrated the ability of TIS to detect "hot" tumors, with a significant correlation of TIS HIGH tumors to ELISPOT-positive y-IFNproducing samples (as shown in Figure $4 \mathrm{~A}, p=0.0002)$. Significant immune GEP differences stratified by TIS ${ }^{\mathrm{HIGH}}$ vs. TIS ${ }^{\mathrm{LOW}}$ included MHC-II $(p=0.017), \gamma$-IFN $(p=0.001)$, TGF $\beta$ $(p=0.011)$, IDO1 $(p=0.023)$, PD-1 $(p=0.002)$, PD-L1 $(p=0.004)$ and PD-L2 $(p=0.0001)$ signatures. Significant cellular GEP differences stratified by TIS ${ }^{\mathrm{HIGH}}$ vs. TIS ${ }^{\mathrm{LOW}}$ included CD8 T cells $(p=0.0001)$, cytotoxic cells $(p<0.0001)$, lymphoid cells $(p=0.001)$, dendritic cells $(p=0.003)$, macrophages $(p=0.003)$, neutrophils $(p=0.004)$, myeloid cells $(p=0.002)$, NK cells $(p=0.007)$ and T cells $(p=0.003)$ A heatmap of twenty-seven significant signature scores is provided in Supplementary File Figure S1. All signature scores are provided in Supplementary File Table S1.

Over 500 genes were examined and differential gene analysis between TIS HIGH and TIS ${ }^{\text {LOW }}$ tumors revealed that CXCL9 (chemokine ligand 9), related to cytokine and chemokine signaling in the lymphoid compartment, and NKG7 (natural killer cell granule protein 7), related to cytotoxic granule exocytosis and inflammation, were significantly higher in TIS ${ }^{\mathrm{HIGH}}$ tumors (log2 fold change of 5.77 and 3.84, respectively, corrected $p=0.0264$ for both) when compared to TIS ${ }^{\mathrm{LOW}}$ tumors (Figure 4B). Although nearly significant $(p=0.055)$, mRNA of CD8A (Cluster of Differentiation 8a), the cytotoxic T cell surface glycoprotein and GZMA (granzyme A), produced by CD8 T cells, were also upregulated 3.53- and 3.62-fold, respectively. A full list of differentially expressed genes in TIS ${ }^{\mathrm{HIGH}}$ vs. TIS ${ }^{\mathrm{LOW}}$ tumors is provided in Supplementary File Table S2.

OS was significantly improved in TIS ${ }^{\mathrm{HIGH}}$ compared to $\mathrm{TIS}^{\mathrm{LOW}}$ (median not reached vs. 5.8 months, one-sided log-rank $p=0.0379$, log-rank HR 0.23 95\% CI: 0.031-1.7) (Figure $4 \mathrm{C}$ ). The 1 -year OS rate was $25 \%$ versus $75 \%$, respectively. Seven of eight $(87.5 \%)$ TIS $^{\mathrm{HIGH}}$ patients demonstrated positive $\gamma$-IFN-ELISPOT reactivity after Vigil treatment compared to one of four (25\%) TIS ${ }^{\text {LOW }}$ patients (Figure 4A). TIS score was significantly associated with $\gamma$-IFN-ELISPOT reactivity $(p=0.0002)$. Patient TIS relationship with survival varied based on the specific immune pathways that were important for each patient's adaptive immune signature and could be important for potential immunotherapy targets (Figure 5). High MHC-II, dendritic cell (DC), myeloid, natural killer (NK) cells and TGF $\beta$ gene expression pre-Vigil treatment were all correlated with significantly longer OS $(p=0.038)$ (Figure 6). Notably, six patients (FANG-OV-1021, -1107, -116, -1086, -1025, 1049) displayed high MHC-II, myeloid, NK cells and TGF $\beta$ gene signatures prior to Vigil treatment and were $\gamma$-IFN-ELISPOT-positive and good responders (OS $>12 \mathrm{mo}$ ) post-treatment (Figure 7A,B). 


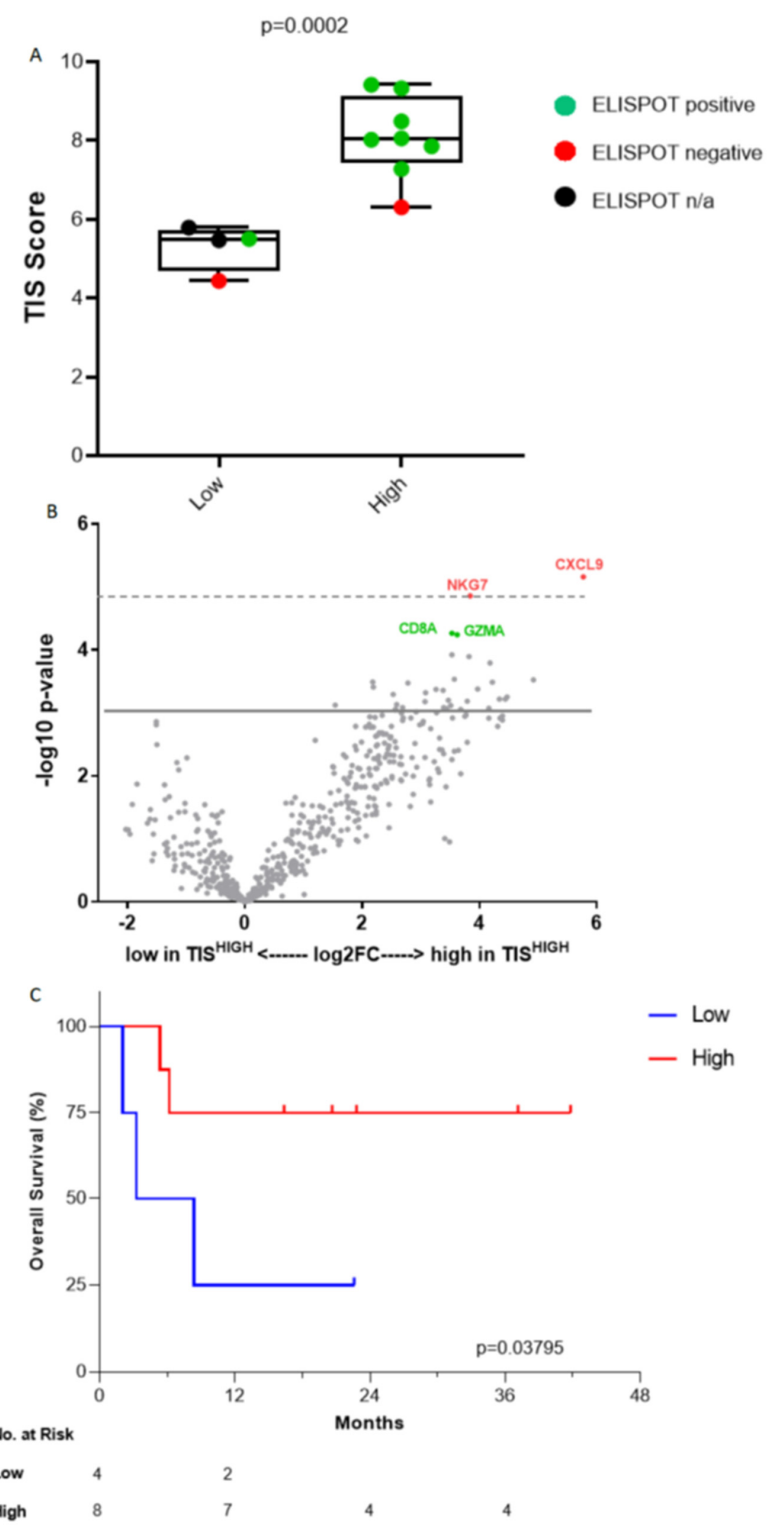

Figure 4. $\gamma$-IFN-ELISPOT reactivity stratified by tumor inflammation score ${ }^{\mathrm{HIGH}}$ (TIS) vs. TIS ${ }^{\mathrm{LOW}}$. Whiskers represent minimum and maximum TIS scores. Statistical analyses of TIS scores were performed using unpaired T-tests with Welch correction. (A) Volcano plot of $p$-value versus $\log 2$ fold change in the differential expression between TIS ${ }^{\mathrm{HIGH}}$ and TIS ${ }^{\mathrm{LOW}}$. The test for differential expression was done by fitting the $\log 2$ normalized count to the response with linear model. The $p$-values were adjusted by the Benjamini and Yekutieli (BY) adjustment. Dots corresponding to genes that are significant at $p<0.5$ (dashed line) are labeled in red. Solid line represents $p<0.10$ (B). Overall survival relationship of Vigil treatment stratified by $\mathrm{TIS}^{\mathrm{HIGH}}$ vs. TIS $^{\mathrm{LOW}}(\mathbf{C})$. 
TISLOW

FANG-032

Overall Survival 3.3 months

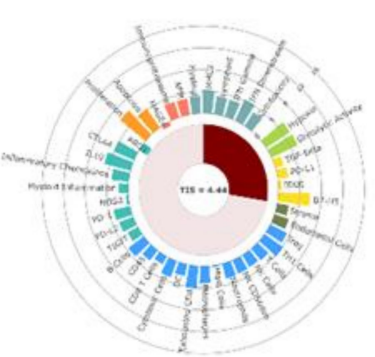

FANG-OV-1024

Overall Survival 20.6 months

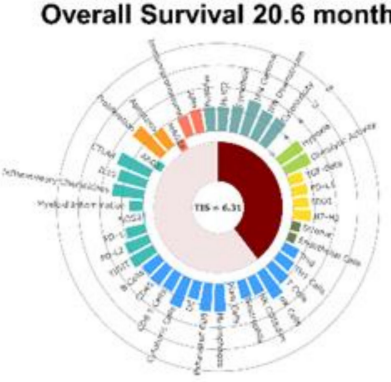

FANG-OV-1049

Overall Survival 41.8 months

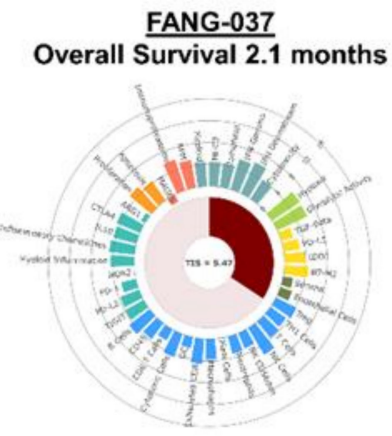

FANG-1107

Overall Survival 16.4 months

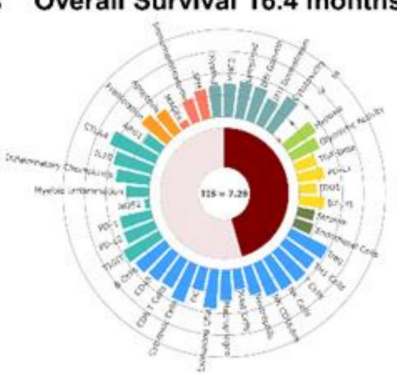

FANG-OV-1122

Overall Survival 5.4 months

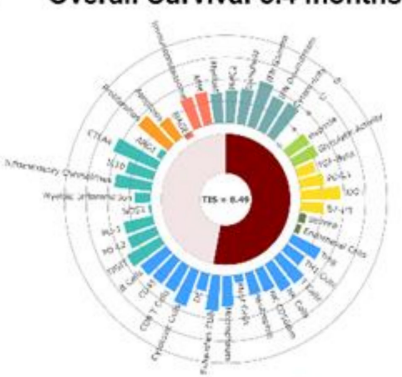

\section{TISHIGH}

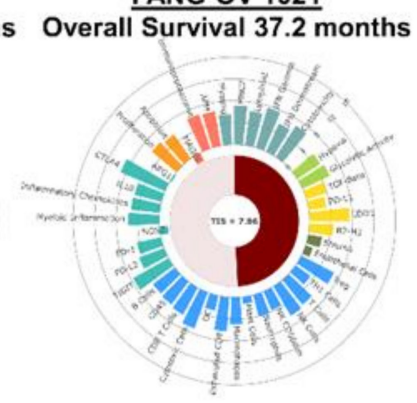

FANG-116

Overall Survival 22.8 months

FANG-046
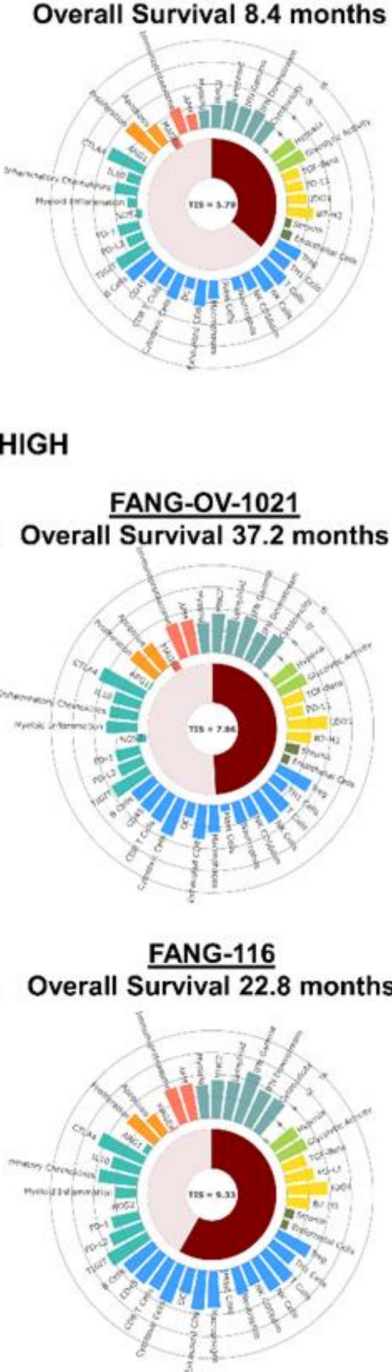

- Anti-Tumor Immune Activity

- Tumor Immunogenicity

- Tumor Sensitivity to Immune Attack

- Inhibitory Immune Signaling

- Immune Cell Population Abundance

- Stromal Factors

III. Inhibitory Tumor Mechanisms

in Inhibitory Metabolism

- TIS
FANG-OV-1091

Overall Survival 22.6 months

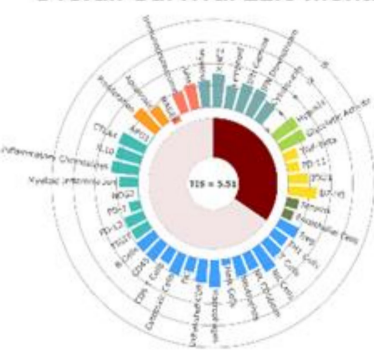

FANG-1086

Overall Survival 22.8 months

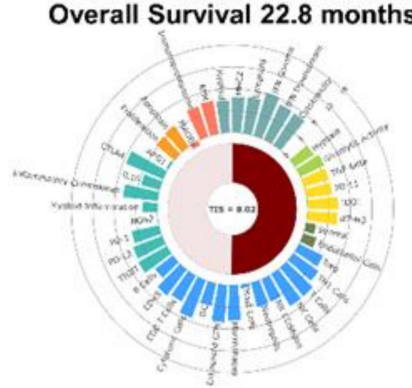

FANG-1025

Overall Survival 6.2 months

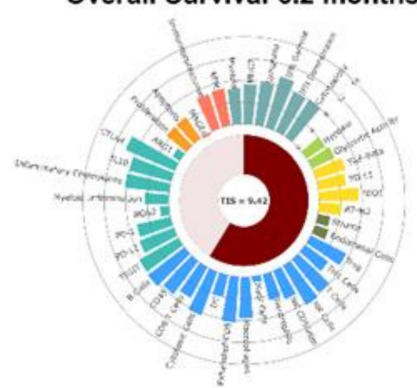

Figure 5. Patient tumor inflammation score (TIS) scores and relationship with survival and immune pathways. 

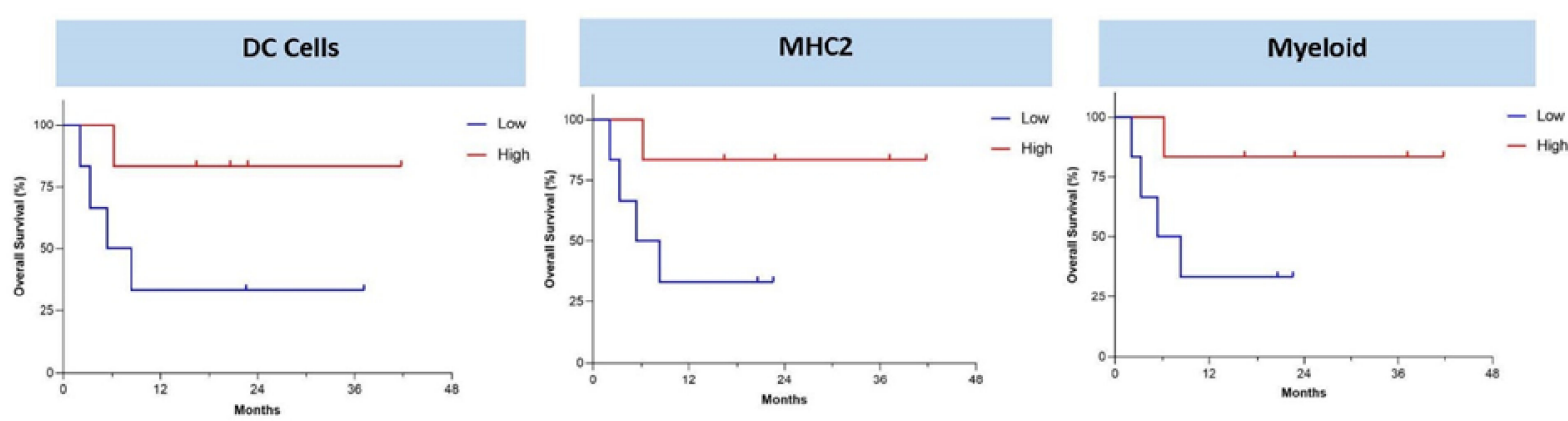

No. at risk

$\begin{array}{lllll}\text { Low } & 6 & 3 & 2 & 2 \\ \text { High } & 6 & 6 & 3 & 3\end{array}$

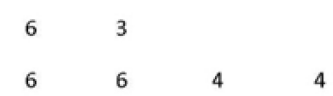

63

High $6 \quad 6 \quad 3 \quad 3$
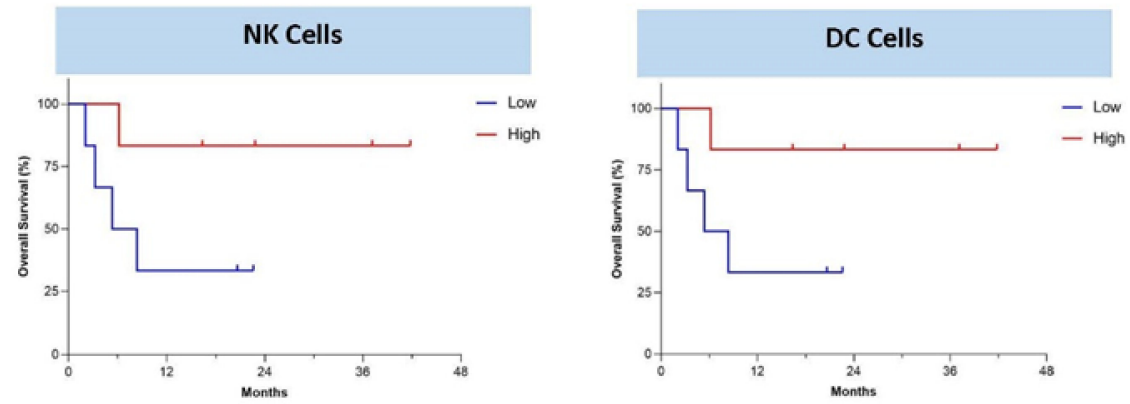

No. at risk

Low 6

$\begin{array}{lllll}\text { High } & 6 & 6 & 4 & 4\end{array}$

Figure 6. Baseline gene signatures correlate with overall survival after Vigil treatment.

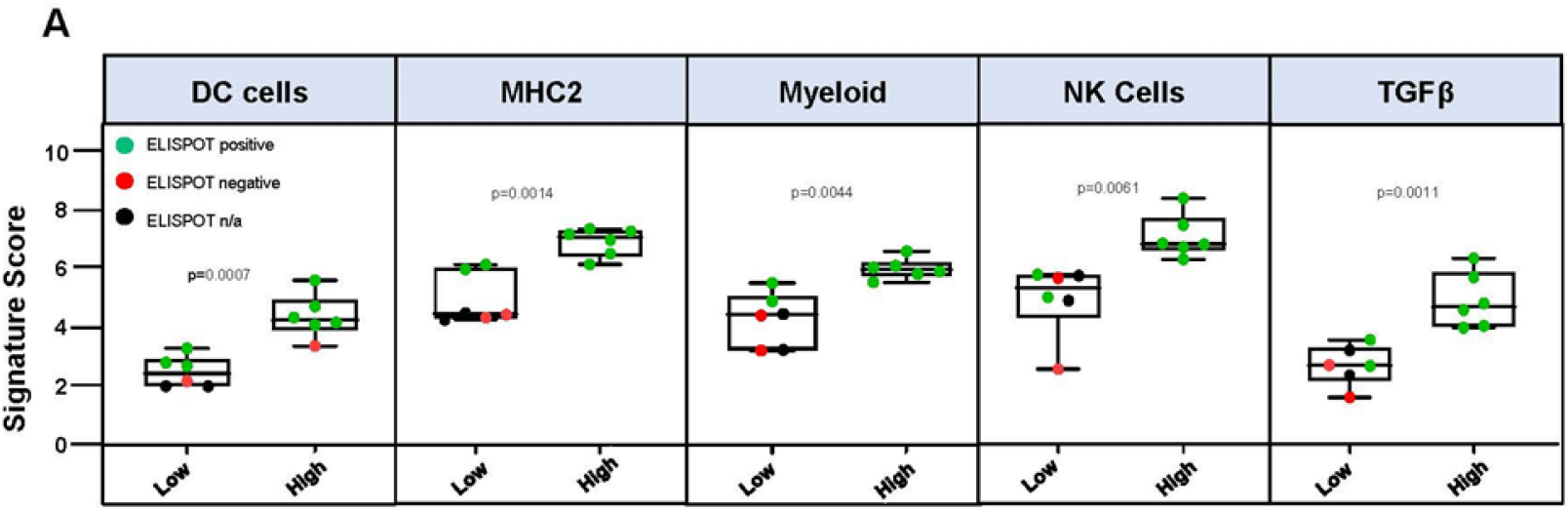

Figure 7. Cont. 
B

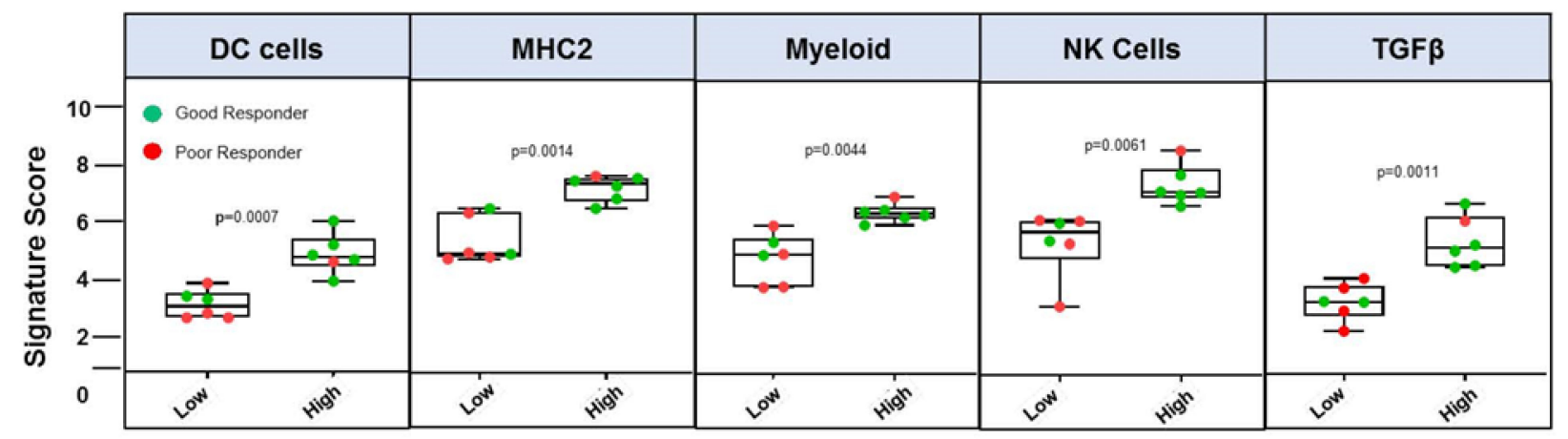

Figure 7. Box plots displaying the distribution of signature scores within the low- and high-expression groups (cutoff = score median) and correlation with (A) ELISPOT reactivity post-Vigil treatment. ELISPOT-positive (green), -negative (red) or not tested (black) patients are displayed. (B) Signature scores within the low- and high-expression groups (cutoff $=$ score median) and correlation with overall survival $>12$ months (GR) or $<12$ months (PR) post-Vigil treatment. GR (green), PR (red) patients are displayed. Whiskers represent minimum and maximum TIS scores. Statistical analyses of TIS scores were performed using unpaired T-tests with Welch correction.

\section{Discussion}

OS assessment at 3 years suggested an advantage in a disparate group of solid tumor patients receiving Vigil. Continued evidence of OS advantage of more than 6 years was demonstrated in a homogenous group of recurrent/refractory ovarian cancer patients treated with Vigil who had a positive $\gamma$-IFN-ELISPOT response. In patients with similar treatment history, median OS at each recurrence has historically been reduced (i.e., first recurrence 17.6 months vs. fourth recurrence 6.2 months) [28]. Currently, there are several treatment options available for relapsed ovarian cancer, including platinum doublet regimens, single-agent chemotherapy (such as pegylated liposomal doxorubicin and topotecan), bevacizumab with or without chemotherapy and olaparib. None of these agents have demonstrated an advantage in relapse-free or overall survival. We did not find a difference in the number of lines of therapy between groups. Despite the small number of patients, the durability of the good response in the immune-activated ( $\gamma$-IFN-ELISPOT) patients could be supportive of long-term memory stimulation by Vigil [14].

$\gamma$-IFN is a key modulator of cell-mediated immunity and controls the fate of T cells to undergo apoptosis or differentiate into memory $\mathrm{T}$ cells [29]. Tumor neoantigens presented by dendritic cells to naïve CD8+ T cells serve as a trigger for CD8+ T cells' differentiation into cytotoxic T lymphocytes. Dendritic cells also activate CD4+ T helper cells through cross-presentation, which is essential for CD8+ T cell activation. Tumor antigen presentation by MHC class I and II molecules is critical to CD8+ and CD4+ T cell-mediated adaptive immune responses [30]. However, escape mechanisms related to this effect have evolved, including a decreased number and infiltration of $\mathrm{T}$ cells into the tumor microenvironment and the exhaustion of dysfunctional T cells [31,32]. Overcoming these deficiencies, converting cold into hot tumors, allows for reactivation of the immune system and antitumor control. Research has focused on increasing the number of $\mathrm{T}$ cells within the tumor microenvironment while also priming them to the individual tumor neoantigens to optimize the antitumor immune response. Increased levels of tumor-infiltrating lymphocytes (TILs) have been correlated with improved clinical responses in a variety of cancers, including ovarian cancer [33-35]. Therefore, several strategies have been employed to increase the number of TILs, including CAR-T cell therapy and vaccination. CAR-T cells modify the patients' $\mathrm{T}$ cells to express targeted receptors to individual antigens. This approach has been successful in treating several hematologic malignancies, including acute lymphoblastic leukemia and large B cell lymphoma [36], although limited with most solid tumors [37]. Vaccination that presents the relevant tumor-specific neoantigens to dendritic cells via MHC-I and MHC-II, thus priming and expanding CD8+ T cells, is also an attractive thera- 
peutic strategy. In this case, $\gamma$-IFN-ELISPOT response coupled with improved OS outcomes supports the hypothesis that Vigil promotes the production of memory T cells. In addition, Vigil use may relate to the education of $\mathrm{T}$ cells and other immune effector cells, as suggested by GEP analysis. This effect may be further enhanced in BRCA wild-type expressive malignancies [38] and may be relevant to the increased clonal neoantigen expression of the tumor, thereby providing more a comprehensive, long-term, antitumor, immune-targeting effect [39].

Opportunities for biomarker-associated Vigil sensitivity related to relevant signal pathway profiles are worth further exploration. Recently, a Phase IIb trial of newly diagnosed patients with stage III/IV ovarian cancer demonstrated greater clinical benefit involving significant advantages in RFS and OS in patients with BRCA1/2 wild-type ovarian cancer [19]. These tumors largely have intact homologous recombination machinery, which hypothetically would result in higher expression of clonal neoantigens compared to $B R C A 1 / 2$ mutant tumors in which DNA repair is maximally disrupted $[38,39]$.

Although y-IFN-related ELISPOT predicted the clinical response to immunotherapy, its results lack specificity, with an overlap between responsive and non-responsive cancers. Furthermore, it lacks the specificity to determine the potential mechanisms of the immune response, which would be the first step in determining a robust predictive biomarker for response. To tease out these subtle differences in immune factors, we performed mRNA gene expression profiling using the NanoString PanCancer IO360 ${ }^{\mathrm{TM}}$ panel on baseline tumor samples of patients that had received Vigil. This technology can digitally count up to 770 unique genes involving cancer cells, microenvironment and immune response. These data are easily translated into immune signatures to determine relevant clinical endpoints of response and survival. Additionally, a TIS incorporates an algorithm of 18 specific functional genes known to be associated with IFN- $\gamma$ expression, which upregulates PD-L1 signaling and other immune modulators [40]. PD-L1 expression is a known biomarker of the response to checkpoint inhibitors that target PD-1, including pembrolizumab [41]. Therefore, high TIS is correlated with the response to immunotherapy [27] in a variety of cancers, particularly renal clear cell carcinoma [42], melanoma [43], lung [44] and head and neck tumors [45]. TIS determines the presence of a pre-existing, peripherally suppressed, adaptive immune response and "hot" vs. "cold" tumors by evaluating the expression of IFN, T-cell exhaustion, natural killer (NK) cells and antigen-presenting-cell-associated genes, such as MHC class I and II [40].

Danaher et al. reported TIS scores across a broad spectrum of cancer types, including ovarian cancer, serving as a pan-cancer measurement of the inflamed tumor [27]. While median TIS scores are higher in tumor types with higher response rates to immunomodulating therapies, within each tumor type, there is considerable inter-sample variability, limiting the applicability of most gene expression algorithms across tumor types. In contrast, because TIS depends primarily on genes expressed by immune cells or in response to immune signaling, it is plausible that its genes' expression levels are driven by the magnitude of a tumor's immune response and not by its cell of origin [40].

We demonstrated in this study the ability of TIS to detect "hot" ovarian cancer tumors, with a significant correlation of TIS ${ }^{H I G H}$ tumors with $\gamma$-IFN-ELISPOT positivity and prolonged OS. Additionally, Vigil-naïve tumors with high numbers of dendritic cells and MHC-II, as well as NK cells, demonstrated extended OS in patients post-Vigil treatment. TIS ${ }^{H I G H}$ tumors demonstrated significantly high mRNA expression of the cytokine and chemokine signaling gene CXCL9 as well as the regulator of NK cell exocytosis gene NKG7. The abundance of antigen-presenting cells and therefore the enhanced expression of MHC-II in treatment-naïve tumors may play a vital role in responsiveness to Vigil, which simultaneously increases MHC-dependent neoantigen presentation and DC maturation through GM-CSF expression. Additionally, tumors of patients with recurrent ovarian cancer showed higher TGF $\beta$ gene signaling in correlation with prolonged survival in response to Vigil. Previous studies have also demonstrated high levels of TGF $\beta$ expression in ovarian cancer cells, which is a core driver of $\mathrm{T}$ regulatory cell signaling and immuno- 
suppression [46-49]. The Vigil plasmid is constructed to silence the expression of furin and downstream TGF $\beta 1 / 2$. Thus, tumor types with high TGF $\beta$ expression or gene signal pathways may increase responsiveness to Vigil treatment, as demonstrated here. The combination of TIS ${ }^{\mathrm{HIGH}}$, MHC-II, high DC, NK cell and TGF $\beta$ signal pathway scores in recurrent ovarian cancer cells appear to be a likely driver of Vigil's specificity to tumor specific neoantigens.

The safety and efficacy of Vigil would support its combination with other therapies with synergistic mechanisms, including checkpoint inhibitors and bevacizumab. Checkpoint inhibitors prevent the interaction between receptor (PD-1 or CTLA-4) and ligand (PD$\mathrm{L} 1$ or CD80/86) in order to reactivate exhausted and expand antigen-specific T cells [50]. Bevacizumab also exerts immune effects, through the regulation of VEGF. VEGF blockade results in increased levels of CD4+ and CD8+ T cells combined with the downregulation of $\mathrm{T}$ regulatory cells [51,52]. Vigil would work in concert with these mechanisms to prime T cells as well as increase CD8+ T cell activity and decrease immune suppression [14]. Another future direction would include stratifying results based on homologous recombination status, either deficient or proficient, which may alter prognosis.

\section{Conclusions}

These results further support the safety and mechanism related to the efficacy of Vigil in ovarian cancer. This work was hypothesis-generating; however, Vigil's unique dual immune stimulatory mechanism supported by $\gamma$-IFN-ELISPOT testing, coupled with vaccination to promote $\mathrm{T}$ cell priming, warrants continued further investigation in a larger cohort of ovarian cancer patients. TIS and its associated pathways hold promise in the discovery of biomarkers to predict the durable responses seen in this 6-year long-term follow-up of recurrent ovarian cancer patients that received Vigil. Biomarker determination via molecular profile assessment and/or NanoString ${ }^{\circledR}$-based characterization is ongoing to define specific populations of patients with cancer and $B R C A 1 / 2$ wild-type gene expression for evidence of further sensitivity or resistance to Vigil.

\section{Summary Points}

- OS at 6 years from tissue procurement was $58 \%$.

- $\quad$ OS benefit was observed in $\gamma$-IFN ELISPOT-positive response (36.8 vs. 23.0 months HR $0.19, p=0.0098$ ).

- $\quad$ TIS $^{\mathrm{HIGH}}$ compared to TIS ${ }^{\mathrm{LOW}}$ demonstrated OS benefit to Vigil treatment (1-year OS 75 vs. $25 \% p=0.03795)$

- Correlated survival benefit of Vigil induced immune response via ELISPOT and relevant indication (TIS > 6, MHC II) using NanoString.

Supplementary Materials: The following are available online at https:/ /www.mdpi.com/article/10 .3390/vaccines9080894/s1, Figure S1: Heat map of twenty-seven significant signature scores and Principal Component Analysis, Table S1: Immune pathway results, Table S2: Gene expression analysis.

Author Contributions: Conceptualization, R.P.R. and J.N.; Data curation, L.M.d.S., R.A.B., G.W. and E.B.; Formal analysis, L.S., L.M.d.S., R.A.B., P.A. and S.H.; Investigation, R.P.R. and A.W.; Methodology, L.M.d.S.; Project administration, R.P.R., G.W. and J.N.; Resources, R.P.R. and E.B.; Supervision, R.P.R. and J.N.; Writing—original draft, L.S., L.M., P.A.; Writing—review and editing, R.P.R., L.S., L.M.d.S., P.A., S.H., G.W., L.M., E.B., A.W. and J.N. All authors have read and agreed to the published version of the manuscript.

Funding: The authors have no outside funding to disclose.

Institutional Review Board Statement: Written documentation of IRB approval of the protocol and consent documents were required before a patient could be registered at any site. Informed patient consent was obtained prior to study enrollment.

Informed Consent Statement: Consent for publication was obtained via the written consent. 
Data Availability Statement: Study data maybe shared upon request and after approval of a data sharing proposal. Proposals that pose a conflict of interest or competitive risk might be declined by Gradalis.

Conflicts of Interest: R.R. reports consulting fees and sponsored research. Luciana Madeira da Silva reports sponsored research.

$\begin{array}{ll}\text { Abbreviations } \\ \text { OS } & \text { overall survival } \\ \text { GEP } & \text { gene expression profile } \\ \text { TIS } & \text { tumor inflammation signature } \\ \text { MHC } & \text { major histocompatibility class } \\ \text { DC } & \text { dendritic cells } \\ \text { NK } & \text { natural killer } \\ \text { PARP } & \text { poly (ADP-ribose) polymerase } \\ \text { PCA } & \text { principal component analysis } \\ \text { GR } & \text { good response }\end{array}$

\section{References}

1. American Cancer Society. Cancer Facts \& Figures 2020. Available online: https://www.cancer.org/content/dam/cancer$\mathrm{org} /$ research/cancer-facts-and-statistics/annual-cancer-facts-and-figures/2020/cancer-facts-and-figures-2020.pdf (accessed on 3 August 2021).

2. Markman, M.; Liu, P.; Wilczynski, S.; Monk, B.; Copeland, L.J.; Alvarez, R.D.; Jiang, C.; Alberts, D. Phase III Randomized Trial of 12 Versus 3 Months of Maintenance Paclitaxel in Patients with Advanced Ovarian Cancer After Complete Response to Platinum and Paclitaxel-Based Chemotherapy: A Southwest Oncology Group and Gynecologic Oncology Group Trial. J. Clin. Oncol. 2003, 21, 2460-2465. [CrossRef]

3. Kehoe, S.; Hook, J.; Nankivell, M.; Jayson, G.; Kitchener, H.; Lopes, A.D.B.; Luesley, D.; Perren, T.; Bannoo, S.; Mascarenhas, M.; et al. Primary chemotherapy versus primary surgery for newly diagnosed advanced ovarian cancer (CHORUS): An open-label, randomised, controlled, non-inferiority trial. Lancet 2015, 386, 249-257. [CrossRef]

4. Torre, L.A.; Trabert, B.; DeSantis, C.E.; Mph, K.D.M.; Samimi, G.; Runowicz, C.D.; Gaudet, M.M.; Jemal, A.; Siegel, R.L. Ovarian cancer statistics, 2018. CA A Cancer J. Clin. 2018, 68, 284-296. [CrossRef] [PubMed]

5. Burger, R.A.; Brady, M.F.; Bookman, M.A.; Fleming, G.F.; Monk, B.J.; Huang, H.; Mannel, R.S.; Homesley, H.D.; Fowler, J.; Greer, B.E.; et al. Incorporation of Bevacizumab in the Primary Treatment of Ovarian Cancer. N. Engl. J. Med. 2011, 365, $2473-2483$. [CrossRef] [PubMed]

6. Messori, A.; Fadda, V.; Maratea, D.; Trippoli, S. Maintenance Chemotherapy in Ovarian Cancer: A Trial-Sequential Analysis. J. Cancer Ther. 2013, 4, 1242-1243. [CrossRef]

7. Coleman, R.L.; Oza, A.M.; Lorusso, D.; Aghajanian, C.; Oaknin, A.; Dean, A.; Colombo, N.; Weberpals, J.I.; Clamp, A.; Scambia, G.; et al. Rucaparib maintenance treatment for recurrent ovarian carcinoma after response to platinum therapy (ARIEL3): A randomised, double-blind, placebo-controlled, phase 3 trial. Lancet 2017, 390, 1949-1961. [CrossRef]

8. Mirza, M.R.; Monk, B.J.; Herrstedt, J.; Oza, A.M.; Mahner, S.; Redondo, A.; Fabbro, M.; Ledermann, J.A.; Lorusso, D.; Vergote, I.; et al. Niraparib Maintenance Therapy in Platinum-Sensitive, Recurrent Ovarian Cancer. N. Engl. J. Med. 2016, 375, $2154-2164$. [CrossRef]

9. Pujade-Lauraine, E.; Ledermann, J.A.; Selle, F.; Gebski, V.; Penson, R.T.; Oza, A.M.; Korac, J.; Huzarski, T.; Poveda, A.; Pignata, S.; et al. Olaparib tablets as maintenance therapy in patients with platinum-sensitive, relapsed ovarian cancer and a BRCA1/2 mutation (SOLO2/ENGOT-Ov21): A double-blind, randomised, placebo-controlled, phase 3 trial. Lancet Oncol. 2017, 18, 1274-1284. [CrossRef]

10. González-Martín, A.; Pothuri, B.; Vergote, I.; Christensen, R.D.; Graybill, W.; Mirza, M.R.; McCormick, C.; Lorusso, D.; Hoskins, P.; Freyer, G.; et al. Niraparib in Patients with Newly Diagnosed Advanced Ovarian Cancer. N. Engl. J. Med. 2019, 381, $2391-2402$. [CrossRef]

11. Poveda, A.; Floquet, A.; Ledermann, J.A.; Asher, R.; Penson, R.T.; Oza, A.M.; Korach, J.; Huzarski, T.; Pignata, S.; Friedlander, M.; et al. Final overall survival (OS) results from SOLO2/ENGOT-ov21: A phase III trial assessing maintenance olaparib in patients (pts) with platinum-sensitive, relapsed ovarian cancer and a BRCA mutation. J. Clin. Oncol. 2020, 38, 6002. [CrossRef]

12. Maples, P.; Kumar, P.; Yu, Y.; Wang, Z.; Jay, C.; Pappen, B.; Rao, D.; Kuhn, J.; Nemunaitis, J.; Senzer, N. FANG Vaccine: Autologous Tumor Cell Vaccine Genetically Modified to Express GM-CSF and Block Production of Furin. Bioprocess. J. 2010, 8, 4-14. [CrossRef]

13. Shi, Y.; Liu, C.H.; Roberts, A.I.; Das, J.; Xu, G.; Ren, G.; Zhang, Y.; Zhang, L.; Yuan, Z.R.; Tan, H.S.W.; et al. Granulocytemacrophage colony-stimulating factor (GM-CSF) and T-cell responses: What we do and don't know. Cell Res. 2006, 16, 126-133. [CrossRef] [PubMed] 
14. Herron, J.; Smith, N.; Stanbery, L.; Aaron, P.; Manning, L.; Bognar, E.; Wallraven, G.; Horvath, S.; Nemunaitis, J. Vigil: Personalized Immunotherapy Generating Systemic Cytotoxic T Cell Response. Cancer Sci. Res. 2020, 3, 1-4. [CrossRef]

15. Senzer, N.; Barve, M.; Kuhn, J.; Melnyk, A.; Beitsch, P.; Lazar, M.; Magee, M.; Oh, J.; Mill, S.W.; Bedell, C.; et al. Phase I trial of "bi-shRNAi(furin)/GMCSF DNA/autologous tumor cell" vaccine (FANG) in advanced cancer. Mol. Ther. 2012, 20,679-686. [CrossRef]

16. Senzer, N.; Barve, M.; Nemunaitis, J.; Kuhn, J.; Melnyk, A.; Beitsch, P.; Magee, M.; Oh, J.; Bedell, C.; Kumar, P.; et al. Long Term Follow Up: Phase I Trial of "bi-shRNA furin/GMCSF DNA/Autologous Tumor Cell" Immunotherapy (FANG ${ }^{\mathrm{TM}}$ ) in Advanced Cancer. J. Vaccines Vaccin. 2013, 4, 209.

17. Oh, J.; Barve, M.; Matthews, C.M.; Koon, E.C.; Heffernan, T.P.; Fine, B.; Grosen, E.; Bergman, M.K.; Fleming, E.L.; DeMars, L.R.; et al. Phase II study of Vigil(R) DNA engineered immunotherapy as maintenance in advanced stage ovarian cancer. Gynecol. Oncol. 2016, 143, 504-510. [CrossRef] [PubMed]

18. Oh, J.; Barve, M.; Senzer, N.; Aaron, P.; Manning, L.; Wallraven, G.; Bognar, E.; Stanbery, L.; Horvath, S.; Manley, M.; et al. Longterm follow-up of Phase 2A trial results involving advanced ovarian cancer patients treated with Vigil@in frontline maintenance. Gynecol. Oncol. Rep. 2020, 34, 100648. [CrossRef]

19. Rocconi, R.P.; Grosen, E.A.; Ghamande, S.A.; Chan, J.K.; Barve, M.A.; Oh, J.; Tewari, D.; Morris, P.C.; Stevens, E.E.; BottsfordMiller, J.N.; et al. Gemogenovatucel-T (Vigil) immunotherapy as maintenance in frontline stage III/IV ovarian cancer (VITAL): A randomised, double-blind, placebo-controlled, phase 2b trial. Lancet Oncol. 2020, 21, 1661-1672. [CrossRef]

20. Disis, M.L.; Taylor, M.H.; Kelly, K.; Beck, J.T.; Gordon, M.; Moore, K.M.; Patel, M.R.; Chaves, J.; Park, H.; Mita, A.C.; et al. Efficacy and Safety of Avelumab for Patients with Recurrent or Refractory Ovarian Cancer: Phase 1b Results from the JAVELIN Solid Tumor Trial. JAMA Oncol. 2019, 5, 393-401. [CrossRef]

21. Matulonis, U.; Shapira-frommer, R.; Santin, A.; Lisyanskaya, A.; Pignata, S.; Vergote, I.; Raspagliesi, F.; Sonke, G.; Birrer, M.; Provencher, D.; et al. Antitumor activity and safety of pembrolizumab in patients with advanced recurrent ovarian cancer: Results from the phase II KEYNOTE-100 study. Ann. Oncol. 2019, 30, 1080-1087. [CrossRef]

22. Varga, A.; Piha-Paul, S.; Ott, P.A.; Mehnert, J.M.; Berton-Rigaud, D.; Morosky, A.; Yang, P.; Ruman, J.; Matei, D. Pembrolizumab in patients with programmed death ligand 1-positive advanced ovarian cancer: Analysis of KEYNOTE-028. Gynecol. Oncol. 2019, 152, 243-250. [CrossRef] [PubMed]

23. Rizvi, N.A.; Hellmann, M.D.; Snyder, A.; Kvistborg, P.; Makarov, V.; Havel, J.J.; Lee, W.; Yuan, J.; Wong, P.; Ho, T.S.; et al. Mutational landscape determines sensitivity to PD-1 blockade in non-small cell lung cancer. Science 2015, 348, 124-128. [CrossRef]

24. Tumeh, P.C.; Harview, C.L.; Yearley, J.H.; Shintaku, I.P.; Taylor, E.J.M.; Robert, L.; Chmielowski, B.; Spasic, M.; Henry, G.; Ciobanu, V.; et al. PD-1 blockade induces responses by inhibiting adaptive immune resistance. Nature 2014, 515, 568-571. [CrossRef] [PubMed]

25. Gubin, M.M.; Zhang, X.; Schuster, H.; Caron, E.; Ward, J.P.; Noguchi, T.; Ivanova, Y.; Hundal, J.; Arthur, C.D.; Krebber, W.J.; et al. Checkpoint blockade cancer immunotherapy targets tumour-specific mutant antigens. Nature 2014, 515, 577-581. [CrossRef] [PubMed]

26. Metsalu, T.; Vilo, J. ClustVis: A web tool for visualizing clustering of multivariate data using Principal Component Analysis and heatmap. Nucleic Acids Res. 2015, 43, W566-W570. [CrossRef] [PubMed]

27. Danaher, P.; Warren, S.; Lu, R.; Samayoa, J.; Sullivan, A.; Pekker, I.; Wallden, B.; Marincola, F.M.; Cesano, A. Pan-cancer adaptive immune resistance as defined by the Tumor Inflammation Signature (TIS): Results from The Cancer Genome Atlas (TCGA). J. Immunother. Cancer 2018, 6, 63. [CrossRef]

28. Hanker, L.C.; Loibl, S.; Burchardi, N.; Pfisterer, J.; Meier, W.; Pujade-Lauraine, E.; Ray-Coquard, I.; Sehouli, J.; Harter, P.; du Bois, A. The impact of second to sixth line therapy on survival of relapsed ovarian cancer after primary taxane/platinum-based therapy. Ann. Oncol. 2012, 23, 2605-2612. [CrossRef] [PubMed]

29. Craig, D.J.; Creeden, J.F.; Einloth, K.R.; Gillman, C.E.; Stanbery, L.; Hamouda, D.; Edelman, G.; Dworkin, L.; Nemunaitis, J.J. Resident Memory T Cells and Their Effect on Cancer. Vaccines 2020, 8, 562. [CrossRef]

30. Leone, P.; Shin, E.-C.; Perosa, F.; Vacca, A.; Dammacco, F.; Racanelli, V. MHC Class I Antigen Processing and Presenting Machinery: Organization, Function, and Defects in Tumor Cells. J. Natl. Cancer Inst. 2013, 105, 1172-1187. [CrossRef]

31. Frey, A.B. Suppression of T cell responses in the tumor microenvironment. Vaccine 2015, 33, 7393-7400. [CrossRef]

32. Cosma, G.; Eisenlohr, L. CD8+ T-cell responses in vaccination: Reconsidering targets and function in the context of chronic antigen stimulation. F1000Research 2018, 7, 508. [CrossRef]

33. James, F.R.; Jiminez-Linan, M.; Alsop, J.; Mack, M.; Song, H.; Brenton, J.D.; Pharoah, P.D.P.; Ali, H.R. Association between tumour infiltrating lymphocytes, histotype and clinical outcome in epithelial ovarian cancer. BMC Cancer 2017, 17, 1-7. [CrossRef] [PubMed]

34. Pagès, F.; Kirilovsky, A.; Mlecnik, B.; Asslaber, M.; Tosolini, M.; Bindea, G.; Lagorce, C.; Wind, P.; Marliot, F.; Bruneval, P.; et al. In Situ Cytotoxic and Memory T Cells Predict Outcome in Patients with Early-Stage Colorectal Cancer. J. Clin. Oncol. 2009, 27, 5944-5951. [CrossRef]

35. Dieu-Nosjean, M.-C.; Antoine, M.; Danel, C.; Heudes, D.; Wislez, M.; Poulot, V.; Rabbe, N.; Laurans, L.; Tartour, E.; De Chaisemartin, L.; et al. Long-Term Survival for Patients with Non-Small-Cell Lung Cancer with Intratumoral Lymphoid Structures. J. Clin. Oncol. 2008, 26, 4410-4417. [CrossRef] 
36. Feins, S.; Kong, W.; Williams, E.F.; Milone, M.C.; Fraietta, J.A. An introduction to chimeric antigen receptor (CAR) T-cell immunotherapy for human cancer. Am. J. Hematol. 2019, 94, S3-S9. [CrossRef] [PubMed]

37. Metzinger, M.N.; Verghese, C.; Hamouda, D.M.; Lenhard, A.; Choucair, K.; Senzer, N.; Brunicardi, F.C.; Dworkin, L.; Nemunaitis, J. Chimeric Antigen Receptor T-Cell Therapy: Reach to Solid Tumor Experience. Oncology 2019, 97, 59-74. [CrossRef] [PubMed]

38. Morand, S.; Stanbery, L.; Walter, A.; Rocconi, R.P.; Nemunaitis, J. BRCA1/2 Mutation Status Impact on Autophagy and Immune Response: Unheralded Target. JNCI Cancer Spectrum 2020, 4, pkaa077. [CrossRef]

39. McGranahan, N.; Furness, A.J.S.; Rosenthal, R.; Ramskov, S.; Lyngaa, R.B.; Saini, S.K.; Jamal-Hanjani, M.; Wilson, G.A.; Birkbak, N.J.; Hiley, C.T.; et al. Clonal neoantigens elicit T cell immunoreactivity and sensitivity to immune checkpoint blockade. Science 2016, 351, 1463-1469. [CrossRef] [PubMed]

40. Ayers, M.; Lunceford, J.; Nebozhyn, M.; Murphy, E.; Loboda, A.; Kaufman, D.R.; Albright, A.; Cheng, J.D.; Kang, S.P.; Shankaran, V.; et al. IFN-gamma-related mRNA profile predicts clinical response to PD-1 blockade. J. Clin. Investig. 2017, 127, $2930-2940$. [CrossRef] [PubMed]

41. Garon, E.B.; Rizvi, N.A.; Hui, R.; Leighl, N.; Balmanoukian, A.S.; Eder, J.P.; Patnaik, A.; Aggarwal, C.; Gubens, M.; Horn, L.; et al. Pembrolizumab for the treatment of non-small-cell lung cancer. N. Engl. J. Med. 2015, 372, 2018-2028. [CrossRef]

42. Motzer, R.J.; Escudier, B.; McDermott, D.F.; George, S.; Hammers, H.J.; Srinivas, S.; Tykodi, S.S.; Sosman, J.A.; Procopio, G.; Plimack, E.R.; et al. Nivolumab versus Everolimus in Advanced Renal-Cell Carcinoma. N. Engl. J. Med. 2015, 373, $1803-1813$. [CrossRef] [PubMed]

43. Topalian, S.L.; Sznol, M.; McDermott, D.F.; Kluger, H.M.; Carvajal, R.D.; Sharfman, W.H.; Brahmer, J.R.; Lawrence, D.P.; Atkins, M.B.; Powderly, J.D.; et al. Survival, Durable Tumor Remission, and Long-Term Safety in Patients with Advanced Melanoma Receiving Nivolumab. J. Clin. Oncol. 2014, 32, 1020-1030. [CrossRef]

44. Reck, M.; Rodríguez-Abreu, D.; Robinson, A.G.; Hui, R.; Csőszi, T.; Fülöp, A.; Gottfried, M.; Peled, N.; Tafreshi, A.; Cuffe, S.; et al. Pembrolizumab versus Chemotherapy for PD-L1-Positive Non-Small-Cell Lung Cancer. N. Engl. J. Med. 2016, 375, 1823-1833. [CrossRef]

45. Ferris, R.L.; Blumenschein, G., Jr.; Fayette, J.; Guigay, J.; Colevas, A.D.; Licitra, L.; Harrington, K.; Kasper, S.; Vokes, E.E.; Even, C.; et al. Nivolumab for Recurrent Squamous-Cell Carcinoma of the Head and Neck. N. Engl. J. Med. 2016, 375, $1856-1867$. [CrossRef]

46. Bierie, B.; Moses, H.L. TGF-beta and cancer. Cytokine Growth Factor Rev. 2006, 17, 29-40. [CrossRef]

47. Kang, Y.; Massague, J. Epithelial-mesenchymal transitions: Twist in development and metastasis. Cell 2004, 118, 277-279. [CrossRef]

48. Li, X.; Ye, F.; Chen, H.; Lu, W.; Wan, X.; Xie, X. Human ovarian carcinoma cells generate CD4(+)CD25(+) regulatory T cells from peripheral CD4(+)CD25(-) T cells through secreting TGF-beta. Cancer Lett. 2007, 253, 144-153. [CrossRef] [PubMed]

49. Creeden, J.; Ong, S.; Gillman, C.; Atkinson, R.; Stanbery, L.; Dworkin, L.; Nemunaitis, J. The Role of TGF $\beta$ in Clinical Cancer Response. Clin. Oncol. Res. 2020, 2020, 1-8. [CrossRef]

50. Pardoll, D.M. The blockade of immune checkpoints in cancer immunotherapy. Nat. Rev. Cancer 2012, 12, 252-264. [CrossRef]

51. Napoletano, C.; Bellati, F.; Landi, R.; Pauselli, S.; Marchetti, C.; Visconti, V.; Sale, P.; Liberati, M.; Rughetti, A.; Frati, L.; et al. Ovarian cancer cytoreduction induces changes in T cell population subsets reducing immunosuppression. J. Cell. Mol. Med. 2010, 14, 2748-2759. [CrossRef] [PubMed]

52. Manzoni, M.; Rovati, B.; Ronzoni, M.; Loupakis, F.; Mariucci, S.; Ricci, V.; Gattoni, E.; Salvatore, L.; Tinelli, C.; Villa, E.; et al. Immunological Effects of Bevacizumab-Based Treatment in Metastatic Colorectal Cancer. Oncology 2010, 79, 187-196. [CrossRef] [PubMed] 